\title{
The Potentials of Chicken Drops in the Remediation of Petroleum Contaminated Agricultural Soil
}

\author{
Reginald Chibueze Ohiri*, Eugene Nwaogwugwu Onyeike and Augustine Amadike Uwakwe \\ Department of Biochemistry, University of Port Harcourt, P. M. B. 5323 East-West Road, Choba, Rivers State, Nigeria
}

\begin{abstract}
A study on the potentials of chicken drops in the remediation of petroleum contaminated agricultural soil was carried out. A total of $18 \mathrm{~m}^{2}$ farmland was divided into three sites of $4 \mathrm{~m}^{2}$ each with $2 \mathrm{~m}$ spaces in between them. Two out of the three sites were polluted with $40 \mathrm{dm}^{3}$ of bonny light crude oil and remediated for 16 weeks. The results showed a total percentage degradation of $72.18 \pm 0.56$ and $59.21 \pm 0.54$ of aliphatic hydrocarbon, $37.92 \pm 0.38$ and $29.58 \pm 0.36$ of polycyclic aromatic hydrocarbon and $5.26 \pm 0.22$ and $0.50 \pm 0.08$ of heavy metals for bioaugmented and natural attenuated sites respectively. However, the highest percentage degradation for aliphatic hydrocarbon was $97.59 \pm 0.95$ for $\mathrm{C}_{24}$ of the bioaugmented site and $92.46 \pm 0.72$ for $\mathrm{C}_{26}$ of the natural attenuated site, while the highest degradation rate for polycyclic aromatic hydrocarbon was $100.00 \pm 0.00$ for Pyrene, Benzo(k)fluoranthene and Benzo(g,h,i)perylene of both the bioaugmented site and natural attenuated site. However, Chromium had the highest percentage degradation rate for the heavy metals with values of $11.95 \pm 0.33$ and $1.12 \pm 0.25$ for the bioaugmented and natural attenuated sites respectively.
\end{abstract}

Keywords: Hydrocarbon; Pollution; Toxicity; Degradation; Remediation

\section{Introduction}

Since the rise of agriculture and forestry in the $8^{\text {th }}$ millennium B.C., there has also arisen by necessity a practical awareness of soils and their management. In the $18^{\text {th }}$ and $19^{\text {th }}$ centuries, the industrial revolution brought increased pressure on soil for the production of raw materials demanded by commerce, while the development of quantitative science offered new opportunities for improved soil management [1]. These initial inquiries expanded into the understanding of soil as complex, dynamic, biogeochemical system that is vital to the life cycle of terrestrial vegetation and soil-inhabiting organisms and by extension to the human race as well. The presence of toxic compounds in soil has increased dramatically due to the accelerated rate of extraction of minerals and fossil fuels and by highly technological industrial processes [1]. Petroleum like all fossil fuels primarily consists of complex mixture of hydrocarbons. Petroleum hydrocarbons are composed of various portions of alkanes (e.g. methane, ethane, etc), aromatics (e.g. benzene, toluene, ethylene and xylene, collectively known as BTEX) and polycyclic aromatics hydrocarbons (PAHs) (e.g. naphthalene, phenanthrene, anthracene and benzo( $\alpha$ )pyrene, etc). Also present in petroleum mixture are organometallo constituents such as Chromium, Cadmium and Nickel [2]. In high concentrations, these hydrocarbons molecules that make up petroleum are highly toxic to many organisms, including humans [3]. The dominance of petroleum products in the world economy creates the conditions for distributing large amounts of these toxicants into populated areas and ecosystem around the globe [4]. Industrial activities release substantial amount of crude oil and refined products into the environment, as a result of accidents such as storage tank leakage, oil spills during routine transportation and shipping operations or sabotage [5]. The contaminant load of soil and water are growing steadily each year in parallel to increasing industrialization and energy demand and therefore necessitate the need for remediation. Hydrocarbonoclastic microorganisms such as bacteria, fungi, yeasts and some algae play paramount roles in bioremediation [6]. These organisms have been isolated from heavily oil polluted deposits or in a variety of soils and water continuously exposed to hydrocarbons for several years [7]. The ability of certain microorganisms to degrade petroleum seems to be an adaptive process that is controlled by environmental conditions [6]. The presence of petroleum may also affect the microbial community through selection of species. Despite decades of research, successful bioremediation of petroleum hydrocarbon contaminated soil remains a challenge [8]. However, Ijah and Antai [9], reported the ability of chicken drop microorganisms in petroleum hydrocarbon remediation and they identified species of Micrococcus, Bacillus, Pseudomonas, Enterobacter, Proteus, Aspergillus, Rhizopus and Penicillium. Pseudomonas aeruginosa CDB-06 and Penicillium CDF-10 as potential crude oil degraders [9]. Ohiri et al. [10] also reported that the application of chicken drops in bioaugmentation of crude oil polluted site raised the $\mathrm{pH}$ of the top soil to a range 6.89 to 7.80 which favours the growth of soil microorganisms thereby enhancing bioremediation. The aim of this research is to assess the potentials of Chicken drops (poultry manure) in the remediation of petroleum contaminated agricultural soil.

\section{Materials}

Eighty litres of bonny light crude oil was obtained from Shell Petroleum Development Company (SPDC) flow station at Egbema, Imo State, Nigeria, while Chicken drops $(40 \mathrm{~kg}$ ) was purchased from Godvine Poultry Farm at Eliozu, Obio Akpor, Rivers State, Nigeria.

\section{Study area}

The study area was located along Eneka-Oyigbo new link road (longitude 70 10" E and latitude 40 40" N) in Obio Akpor Rivers State, Nigeria. The soil of this area belongs to the ultisols. Approximately the

*Corresponding author: Reginald Chibueze Ohiri, Department of Biochemistry, University of Port Harcourt, P. M. B. 5323 East-West Road, Choba, Rivers State, Nigeria, Tel: +2348038808077; E-mail: raycohiri@yahoo.com

Received May 02, 2013; Accepted August 23, 2013; Published August 26, 2013

Citation: Ohiri RC, Onyeike EN, Uwakwe AA (2013) The Potentials of Chicken Drops in the Remediation of Petroleum Contaminated Agricultural Soil. J Environ Anal Toxicol 3: 187. doi:10.4172/2161-0525.1000187

Copyright: (C) 2013 Ohiri RC, et al. This is an open-access article distributed under the terms of the Creative Commons Attribution License, which permits unrestricted use, distribution, and reproduction in any medium, provided the original author and source are credited. 
entire area consisted of deep uniform sand and clay sand, with slightly humus topsoil and a top soil $\mathrm{pH}$ of approximately $4.86 \pm 0.12$. There was no record of oil spillage or pipeline vandalization in the study area.

\section{Pollution and bioremediation of research site}

Approximately $18 \mathrm{~m}^{2}$ farmland was cleared and divided into three sites of $4 \mathrm{~m}^{2}$ each with $2 \mathrm{~m}$ spaces in between them. These sites were polluted with $40 \mathrm{dm}^{3}$ of bonny light crude oil and bioremediated for 16 weeks as follows: Site A (Control site) was an unpolluted $4 \mathrm{~m}^{2}$ farmland, while site B (Bioaugmented site) was a $4 \mathrm{~m}^{2}$ farmland polluted with 40 $\mathrm{dm}^{3}$ of bonny light crude oil and bioaugmented with $40 \mathrm{~kg}$ of chicken drops. However, site C (Natural attenuated site) was polluted with 40 $\mathrm{dm}^{3}$ of bonny light crude oil.

\section{Collection of soil sample}

Soil samples were collected by the method Bashour and Sayegh [11]. Where a sterilized soil auger was used to make a depth of $20 \mathrm{~cm}$ using a grid. The samples for biochemical analyses were collected with unused and sterilized plastic bags sealed with rubber bands. All samples were labelled with a permanent water resistant marker and were taken to the laboratory within 1 hour of collection for analysis. The samples were collected from both the control and the polluted sites as follows:

Topsoil (0-10 cm depth): Samples were collected form the three sites at week 0 and week 16 from date of pollution.

Subsoil (15-20 cm depth): Samples were collected form the three sites at week 0 and week 16 from date of pollution.

\section{Determination of aliphatic and polycyclic aromatic hydrocarbons (PAH) in leaf samples}

Extraction of soil samples for aliphatic and polycyclic aromatic hydrocarbons was done by modified method of the Association of Official Analytical Chemist [12]. Composite soil samples from the control and bioremediated sites were air dried and $1.0 \mathrm{~g}$ of sample was placed in a separation funnel. Ten millilitres of dichloromethane was added. The mixture was homogenized by stirring with a glass rod and was subsequently poured into a chromatography column packed with glass wool, silica-gel and $0.5 \mathrm{~cm}^{3}$ of anhydrous sodium sulphate. One millilitre of the eluent was transferred into a $10 \mathrm{~mm}$ (internal diameter) $\times 250 \mathrm{~mm}$ long chromatographic column packed with glass wool. Slurry of $2 \mathrm{~g}$ activated silica in $10 \mathrm{ml}$ methylene chloride and $0.5 \mathrm{~cm}^{3}$ of sodium sulphate were made at the top of the column. The column was pre-eluted with $20 \mathrm{ml}$ of concentrated dichloromethane for 2.0 min and $1.0 \mathrm{ml}$ of the initial eluent was then added. A volume of $1 \mathrm{ml}$ dichloromethane was introduced at the receiving end of the column and the stop-cork was opened. The final eluent was collected into a 10 $\mathrm{ml}$ graduated cylinder. The extract was concentrated in a water-bath at a temperature of $40^{\circ} \mathrm{C}$ and $1.0 \mathrm{ml}$ of dichloromethane was added to the concentrated extract (to dissolve it), then $1 \mu \mathrm{l}$ portion of the dissolved extract was collected with a hypodermic string and injected through a rubber septum at the injection point of the gas chromatography manufactured by Hewleltt and Packard (hp), model: HP 5890 Series II. After injection, separation occurred as the vapour constituent partition between the gaseous and liquid phase. Signals were obtained in the form of chromatogram as the vapour phase of the injected extract was being ionized for the fractionating components of aliphatic hydrocarbon or polycyclic aromatic hydrocarbon (PAH). Gas chromatography conditions for determination of aliphatic hydrocarbon were initial and final oven temperatures of $50^{\circ} \mathrm{C}$ and $310^{\circ} \mathrm{C}$. Injection temperature was $275^{\circ} \mathrm{C}$ while detector temperature was $320^{\circ} \mathrm{C}$. The gas chromatography was calibrated with Accustandard aliphatic hydrocarbons at $100 \mathrm{ppm}$. Gas chromatography condition for the determination of polycyclic aromatic hydrocarbon was initial and final oven temperatures of $65^{\circ} \mathrm{C}$ and $310^{\circ} \mathrm{C}$. Injection temperature was $275^{\circ} \mathrm{C}$ while detector temperature was $375^{\circ} \mathrm{C}$. The gas chromatography was also calibrated with Accustandard polycyclic aromatic hydrocarbons at $2000 \mathrm{ppm}$.

\section{Determination of Heavy metal contents of vegetable leaves}

Heavy metal contents of soil samples were determined by the emission spectroscopymethod. 8

Principle: Sample digests were burned in a carbon arc, causing each element to emit a unique wavelength of light. The density of light emitted by each element is directly proportional to the concentration of the element in the sample.

Apparatus: Arc-spark emission spectrography, Analytical weighing balance, Furnace, $10 \mathrm{ml}$ Porcelain crucibles, $50 \mathrm{ml}$ Burette, Drying oven, Wiley mill, volumetric flasks and Pipettes.

Reagents: Lithium carbonate $\left(\mathrm{LiCO}_{3}\right)$ use for the analysis was obtained from Sigma Aldrich, MO USA.

Procedure: A quantity of $1.0 \mathrm{~g}$ of dried soil samples were ground and placed in $10 \mathrm{ml}$ porcelain crucibles. The crucibles were placed in a cool muffle furnace and the samples were ashed at a temperature of $500^{\circ} \mathrm{C}$ for 4 hours. The crucibles were removed and allowed to cool. Then $5.0 \mathrm{ml}$ of lithium carbonate buffer was added and swirled gently to dissolve the ash. The digest was transferred to a Teflon boat and analysed on a direct reading arc-spark emission spectrography.

\section{Results and Discussions}

The results of this study showed great variation in the ability of chicken drops in the remediation of crude oil polluted soil. The increase in percentage remediation of both aliphatic and aromatic hydrocarbons observed in the bioaugmented site (Figure 1 and 2), may be attributed to the presence of aerobicheterotrophs, total fungi and species of crude oil degrading bacteria such as Micrococcus, Bacillus, Pseudomonas, Enterobacter, Proteus, Aspergillus, Rhizopus and Penicillium in the chicken drop [9]. Microbial degradation of contaminants has been reported to be a factor of contaminant concentration, bioavailability and nutrient availability [13]. Moreover, chicken drops contains about $2.3 \%$ total nitrogen, $0.5 \%$ available phosphorus and $18.5 \%$ moisture content in addition to other nutrients [9]. This nutrient availability

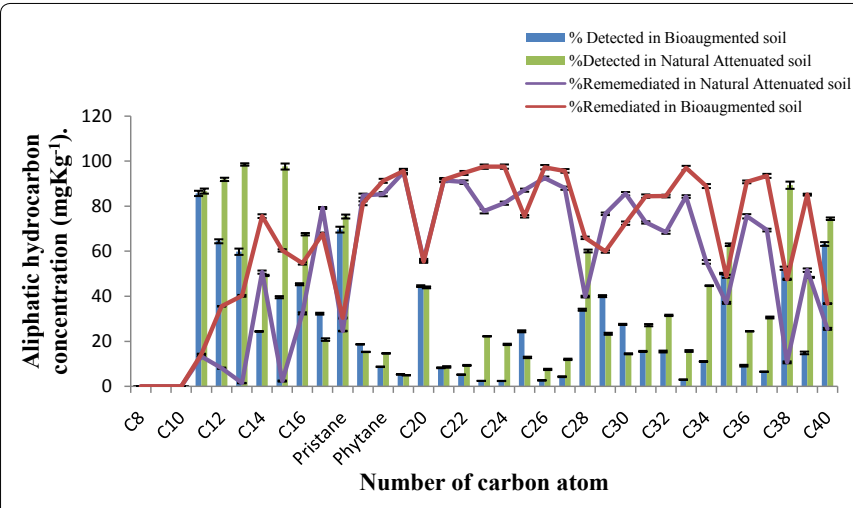

Values plotted are means \pm standard deviations of triplicate determinations

Figure 1: Percentage degradation of aliphatic hydrocarbon after 16 weeks of bioremediation. 
may have also resulted to increase in percentage remediation of both aliphatic and polycyclic aromatic hydrocarbons observed in the bioaugmented site (Figure 1 and 2).

Aliphatic hydrocarbons are preferably degraded under aerobic conditions than polycyclic aromatic hydrocarbons [13]. However, the reduced degradation rate of polycyclic aromatic hydrocarbons as compared to the aliphatic hydrocarbons (Figure 1 and 2) may be attributed to poor aerobic degradation of polycyclic aromatic hydrocarbons which is analogously effected by the degradation of mononuclear aromatics with the individual rings being degraded one after the other [13]. Immobilization of polycyclic aromatic hydrocarbons in the presence of other contaminants has been reported [13]. These hydrocarbons tend to form aggregates which are poorly supplied with oxygen, thereby reducing aerobic degradation [13]. This may also be responsible for the reduced degradation rate of polycyclic aromatic hydrocarbons as compared to the aliphatic hydrocarbons (Figure 1 and 2).

The reduced remediation rate of Indeno(1,2,3)pyrene, Chrysene, Fluorene and Anthracene (Figure 2) may be attributed to the low solubility of these polycyclic aromatic hydrocarbons which may result to a decline in bioavailability, thus the threshold concentration for degradation may not be reached. Sequel to this, higher condensed polycyclic aromatic hydrocarbons may scarcely serve as carbon and energy sources [13]. Moreover, the $100 \%$ degradation rate recorded for Pyrene, Benzo(k)fluranthene and Benzo(g,h,i)perylene can be attributed to the presence of high catabolic microbial superbugs that enhances either their degradation or enzymatic cleavage of some rings, thereby generating other polycyclic aromatic hydrocarbons such as Naphthalene. This may be responsible for the increased detection rate of Naphthalene when compared to Acenaphthylene and Acenaphthene (Figure 2). However, the degradation of some low-molecular polycyclic aromatic hydrocarbons such as Naphthalene, Acenaphthylene and Acenaphthene can takes place under anaerobic conditions, dominated by co-metabolic degradation reactions [13]. Thus the increase in percentage remediation of acenaphthylene and acenaphthene may be attributed to the addition chicken drops (poultry manure) which may generate a co-metabolic degradation process, thereby increasing the rates of degradation ofthese low-molecular polycyclic aromatic hydrocarbons (Figure 2).

However, bacterial biosurfactant has been proven effective in enhancing the solubility and biodegradation of petroleum hydrocarbons including Polycyclic aromatic hydrocarbons [14,15]. Microbial production of biosurfactant has been linked to the utilization of available hydrophobic substrates by the producing microbes from their natural habitat, presumably by increasing the surface area of substrates and increasing their apparent solubility [16,17].Therefore the presence of high microbial population in the chicken drops and their subsequent production of biosurfactant may be responsible for the percentage increase polycyclic aromatic degradation of the bioaugmented site as compared to the natural attenuated site (Figure 2).

The low percentage degradation rate of heavy metals observed in this research (Figure 3) may be attributed to adversely affect of toxic metals to potentially important biodegradation processes occurring in the environment [18]. Such metallic compounds appeared to be considerably more inhibitory to the biodegradation of an organic chemical than high concentrations of microbial toxic organics [19]. However, the poisonous nature of some heavy metals such as arsenic has long been reported but its mode of toxicity depends very

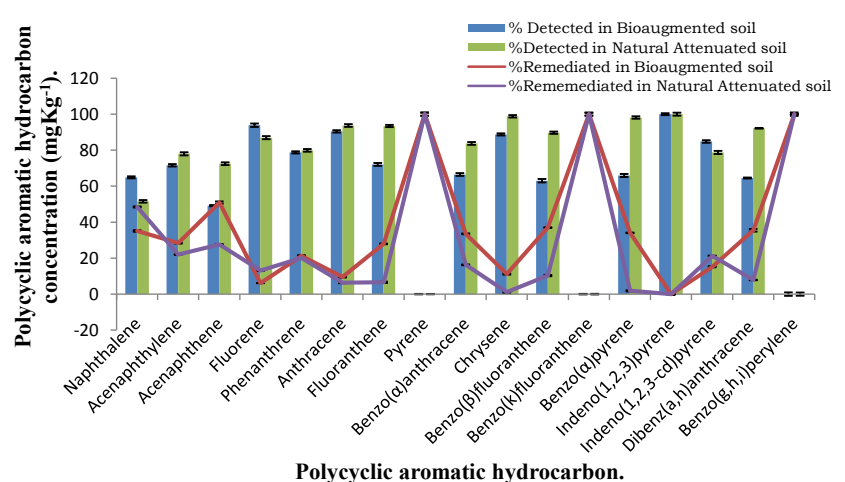

Values plotted are means \pm standard deviations of triplicate determinations

Figure 2: Percentage degradation of polycyclic aromatic hydrocarbon after 16 weeks of bioremediation.

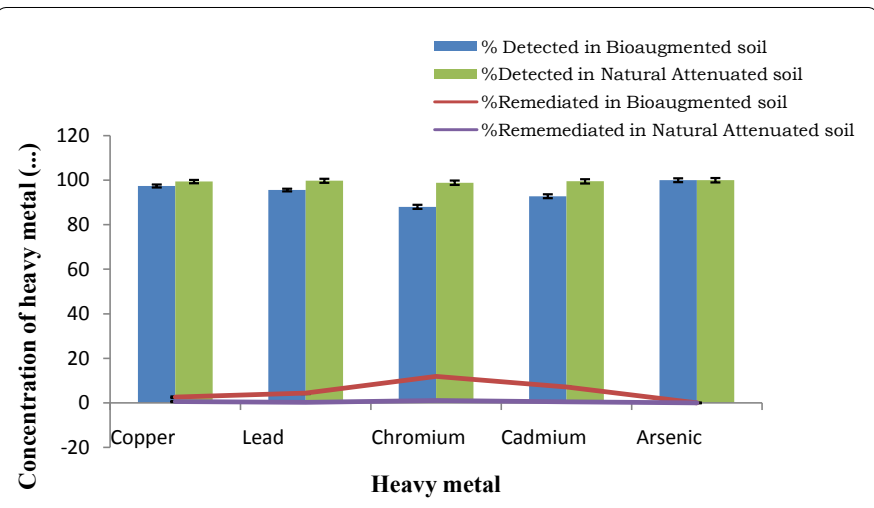

Values plotted are means \pm standard deviations of triplicate determinations

Figure 3: Percentage degradation of heavy metals after 16 weeks of bioremediation.

much on the chemical form of the metalloid [20]. Arsenate has been reported to mimic phosphate and can therefore enter the microbial cell via transporters meant for the uptake of this essential nutrient and subsequently interferes with phosphate-based energy-generating processes, and as a result inhibits oxidative phosphorylation [21]. Arsenite, on the other hand, enters via aqua-glycerolporins and targets a broader range of cellular processes, binding to the thiol groups in important cellular proteins such as pyruvate dehydrogenase and 2-oxoglutarate dehydrogenase [21]. However, these transport and toxicity mechanisms culminate to a reduced degradation of heavy metals as observed in this research (Figure 3). In conclusion, the results of this study encourage the use of chicken drops in bioremediation, especially in the remediation of aliphatic hydrocarbons. However, a combined remediation approach involving a sequential application of nutrient augmentation, microbial seeding and phytoremediation methods should be encouraged as a single step remediation process in crude oil abatement programme.

\section{References}

1. Sposito G (2008) The chemistry of soils, 2nd edn, Oxford University Press, London 37.

2. Van Hamme DJ, Singh A, Ward OP (2003) Recent advances in petroleum microbiology. Microbiol Mol Biol Rev 64: 503-549.

3. Alexander M (1994) Biodegradation and bioremediation. Academic Press, NewYork 692 
Citation: Ohiri RC, Onyeike EN, Uwakwe AA (2013) The Potentials of Chicken Drops in the Remediation of Petroleum Contaminated Agricultural Soil. J Environ Anal Toxicol 3: 187. doi:10.4172/2161-0525.1000187

Page 4 of 4

4. Ojumu T, Bello OO, Sonibare JA, Solomon BO (2004) Evaluation of microbial systems for bioremediation of petroleum refinery effluents in Nigeria. African $\mathrm{J}$ Biotech 1: 31-35.

5. Serrano A, Gallego M, Gonza'Lez JL, Tejada M (2008) Natural attenuation of diesel aliphatic hydrocarbons in contaminated agricultural soil. J Environ Pollut 144: 203-209.

6. Nkwelang G, Kamga HFL, Nkeng GE,Antai SP (2008) Studies on the diversity, abundance and succession of hydrocarbon utilizing micro organisms in tropical soil polluted with oily sludge. African Journal of Biotechnology 7: 1075-1080.

7. Ibe NS, Ibe EG (1992) Control and dispersion potential of oil spills by microbial seeding in the petroleum industry and the Nigerian environment. Proceeding of an International seminar, Petroleum Training Institute (PTI). Warri Nigeria $112-115$

8. Rahman KSM, Thahira-Rahman J, Kourkoutas Y, Petsas I, Marchant R, et al. (2003) Enhanced bioremediation of $n$-alkanes in petroleum sludge using bacterial consortium amended with rhamnolipid and micronutrients. Bioresour Technol 90: 159-168.

9. ljah UJJ, Antai SP (2003) The potential use of chicken-drop microorganisms for oil spill remediation. J. Environ. 23: 89-95.

10. Uwakwe AA, Onyeike EN, Ohiri RC (2012) pH variations and lipase activities of crude oil bioremediated agricultural soil. Int Jour Curr Res 4: 34-37.

11. Bashour II, Sayegh AH (2007) Methods of analysis for soils of arid and semiarid regions. Food and Agriculture Organization of the United Nations (FAO), Rome, Italy 15-22.
12. Association of Official Analytical Chemists (AOAC) (2006) Official methods of analysis. Asso Off Anal Chem Virginia, USA.

13. International Centre for Soil and Contaminated Sites (ICSS) (2006) Manual for biological remediation techniques. German Federal Environmental Agency, Dessau, Germany 23-26.

14. Cybulski Z, Dziurla E, Kaczorek E, Olszanowski A (2003) The influence of emulsifers on hydrocarbon biodegradation by Pseudomondacea and Bacillacea strains. Spill Sci Technol Bull 8: 503-507.

15. Wong JWC, Fang M, Zhao Z, Xing B (2004) Effect of surfactants on solubilization and degradation of phenenthrene under thermophilic conditions. J Environ Qual 33: 2015-2025.

16. Maier RM (2003) Biosurfactant: Evolution and diversity in bacteria. Adv Appl Microbiol 52: 101-121.

17. Mukherjee AK, Das K (2005) Correlation between diverse cyclic lipopeptides production and regulation of growth and substrate utilization by Bacillus subtilis strains in a particular habitat. FEMS Microbiol Ecol 54: 479-489.

18. Said WA, Lewis DL (1991) Quantitative assessment of the effects of metals on microbial degradation of organic chemicals. Appl Environ Microbiol 57: 14981503.

19. Hwang HM, Hudson RE, Lewis DL (1989) Assessing interactions of organic compounds during biodegradation ofcomplex waste mixtures by naturally occurring bacterial assemblages. Environ Toxicol Chem 8: 209-214.

20. Silva JJR, Williams RJP (1993) The Biological Chemistry of the Elements: The inorganic chemistry of life. Clarendon Press, Oxford, London.

21. Lloyd JR, Oremlands RS (2006) Microbial transformation of arsenic in the environment: From soda lakes to aquifers. Elements 2: 85-90. 